\title{
GOMMENTARY
}

— How Do We Teach? -

\section{The Case for 3 Years of Family Medicine Residency Training}

Donald Raj Woolever, MD

(Fam Med. 2021;53(7):603-5.)

doi: 10.22454/FamMed.2021.222197

Published Online First May 26, 2021

$\mathbf{T}$ he duration of family medicine residency training in the United States has been 3 years since the inception of the discipline in 1969. Family medicine training around the world ranges from 2 to 5 years, with varying approaches to undergraduate and predoctoral education. Much has changed in US medicine since 1969 , yet the core values of family medicine have remained consistent. While adjustments in curricula, structure, and sequence may be warranted, 3 years remains the appropriate length of training for family medicine residents. A longer duration of training poses significant challenges at the same time that learners need more choice and flexibility. Innovation in training requires creative thought, reforms, and adaptability, without increasing the length of training.

\section{Continued Demand for 3 Years of Training}

The 3-year family medicine residency experience allows for a graded exposure to key elements of training while also ensuring ready access to care for patients and communities. This is validated by sustained demand for the graduates of 3-year programs and the demand for additional training slots. In 2020, the physician recruiting firm of Merritt Hawkins identified family medicine as "the most in-demand specialty" by employers for 14 consecutive years. ${ }^{1}$ The Medical Group Management Association has shown a $15 \%$ increase in family physician salaries to a median of $\$ 250,000$ for outpatient practice in $2020 .{ }^{2}$ At the same time, to meet the demand of trainees, the number of 3-year family medicine residencies has grown at approximately $3.5 \%$ per year, adding 99 new programs since $2018 .{ }^{3}$

\section{Longer Duration of Training Poses Many Challenges}

The current infrastructure is built with resources and funding to support 3 years of family medicine residency. Increasing the duration would result in a longer pipeline and a delay in graduating family physicians prepared to serve their communities. A 1-year increase in training would result in approximately 4,500 fewer family medicine graduates. Even if spread over several years, that would represent a significant loss of new graduates at a time when the United States is projected to have a shortage of 55,000 family physicians. ${ }^{4}$

For community-based family medicine residencies, the increase in unfunded requirements and staffing needs of additional training would prove to be a significant burden. At the national average of $\$ 150,000$ per year per resident, even small programs could see a large increase in expenses. ${ }^{5}$ Although some 4-year programs have reported financial stability, most depend on increased clinical volume or novel funding sources. ${ }^{6}$

Beyond the financial barriers, adequate clinical experiences and patient volumes, along with the concern for availability of clinical faculty, all pose significant hurdles. Accreditation Council for Graduate Medical Education data

From the Maine-Dartmouth Family Medicine Residency, Augusta, ME 
already shows declines in the number of continuity visits, pediatric visits, and continuity obstetrical deliveries managed by family medicine residents. ${ }^{7}$ Additional teaching needs would further exacerbate the existing challenges of recruiting new faculty to communitybased and rural programs.

\section{Learner Choice and Flexibility}

A change in length of training may also result in an overall decrease in the number of medical school seniors seeking family medicine residency positions. The existing structure maintains medical student interest and acknowledges the paradigm of educational debt. The Association of American Medical Colleges reported a median medical student debt burden of $\$ 200,000$ in $2020 .^{8}$ An increase in residency length would mean a delay to full income potential. Although family medicine salaries have risen steadily, the discipline remains among the lowest paid, and a nearly $\$ 200,000$ pay differential between resident and attending physician, balanced against an average $\$ 200,000$ educational debt is significant. The path to becoming a physician, already a long and expensive journey, could lead some students to choose a 3-year training program in a different specialty.

\section{Reform Without Increasing the Length of Training}

The discipline should emphasize the quality of training rather than the quantity of time. A recent survey of family medicine faculty and residents showed a clear preference for maintaining 3 years of training with $74 \%$ of faculty and $77 \%$ of residents preferring 3 years or 3 years with an optional fourth year of training. ${ }^{9}$ Longer length of training does not necessarily lead to increased knowledge. A recent study comparing emergency medicine residents in 3- or 4-year programs found no difference in board exam scores. ${ }^{10}$

There is a need for reexploration of the contents of the 3 years of family medicine training. While comprehensiveness remains a hallmark of family medicine, the current breakdown of training time is not reflective of the practice patterns for the majority of family physicians. ${ }^{11}$ A strategic decrease in the time required in experiences such as inpatient pediatrics, and a refocus on high-functioning outpatient clinics would more closely reflect the future needs of graduates. Only $24.1 \%$ of respondents to a recent survey felt that it was still important to teach inpatient pediatrics to family medicine residents. ${ }^{12}$ Use of "selective" or "area of concentration" opportunities could provide more cohesive learning experiences in important areas such as health equity and advocacy. This calls for a change in specific rotation requirements, different approaches to teaching and evaluation, and more flexibility in the overall curriculum, but it does not require an increase in length of training. Ultimately, flexibility should remain with the learner. There are ample fellowship and advanced degree opportunities for those who desire additional time for structured learning. The number of family medicine residents who choose to pursue fellowships is relatively small. ${ }^{13}$

Three years of family medicine residency is producing well-trained family physicians. Keeping the needs of patients, communities, and physicians at the forefront, learners should be able to determine for themselves the type and timing of any additional training. Ultimately, flexibility and autonomy will provide a consistent pipeline of well-trained, satisfied, and engaged family physicians to serve their patients and communities for generations to come.

ACKNOWLEDGEMENTS: The author acknowledges the assistance of Aaron George, DO, FAAFP, Meritus Health, Hagerstown, Maryland; and Deborah Taylor, $\mathrm{PhD}$, North Ft Myers, Florida.

CORRESPONDENCE: Address correspondence to Dr Donald Raj Woolever, MD, Director, Maine-Dartmouth Family Medicine Residency, 15 East Chestnut Street, Augusta, ME 04330. 207-798-9756. raj.woolever@mainegeneral.org.

\section{References}

1. Merritt Hawkins Review of Physician and Advanced Practitioner Recruiting Incentives. Dallas, TX: Merritt Hawkins; 2020.

2. 2020 Physician Compensation Benchmarks. Englewood, CO: Medical Group Management Association; 2020.

3. Accreditation Council for Graduate Medical Education Family Medicine Review Committee, Chicago, IL. Accessed March 2021.

4. The Complexities of Physician Supply and Demand: Projections From 2018 to 2033. Washington, DC: Association of American Medical Colleges; 2020. https://www.aamc. org/data-reports/workforce/data/complexities-physiciansupply-and-demand-projections-2018-2033. Accessed April $23,2021$.

5. Regenstein M, Nocella K, Jewers MM, Mullan F. The cost of residency training in teaching health centers. N Engl J Med. 2016;375(7):612-614. doi:10.1056/NEJMp1607866

6. Douglass AB, Barr WB, Skariah JM, et al. Financing the fourth year: experiences of required 4-year family medicine residency programs. Fam Med. 2021;53(3):195-199. doi:10.22454/FamMed.2021.249809 
7. Hoekzema G. Trends in Family Medicine Residency Clinical Data from ACGME WebADS. Starfield Summit Position Paper. December 2020.

8. Youngclaus J, Fresne JA. Physician Education Debt and the Cost to Attend Medical School: 2020 Update. Washington, DC: Association of American Medical Colleges, 2020 https://store.aamc.org/downloadable/download/sample/ sample_id/368/. Accessed April 23, 2021.

9. American Board of Family Medicine Survey of Residency Faculty and Diplomates: Preliminary Results, 2020. Lexington, KY: ABFM; 2020.

10. Hopson L, Regan L, Gisondi MA, Cranford JA, Branzetti J. Program director opinion on the ideal length of residency training in emergency medicine. Acad Emerg Med. 2016;23(7):823-827. doi:10.1111/acem.12968
11. Coutinho AJ, Phillips RL Jr, Peterson LE, Peterson LE. Intended vs reported scope of practice. JAMA. 2016;315(20):2234-2235. doi:10.1001/jama.2016.1727

12. Newton W, Mitchell K. Re-Envisioning Family Medicine Education. Residency Leadership Summit Pisacano Plenary. March 2021.

13. Sairenji T, Dai M, Eden AR, Peterson LE, Mainous AG III. Fellowship or further training for family medicine residents? Fam Med. 2017;49(8):618-621. 